\title{
On the future of controllable fluid film bearings
}

\author{
ILMAR FERREIRA SANTOS \\ Dept of Mechanical Engineering, Technical University of Denmark, Building 404, 2800 Lyngby, Denmark
}

Received 9 November 2010, Accepted 26 February 2011

\begin{abstract}
This work gives an overview of the theoretical and experimental achievements of mechatronics applied to fluid film bearings. Compressible and uncompressible fluids are addressed. Rigid and elastic (deformable) bearing profiles are investigated. Hydraulic, pneumatic, magnetic and piezoelectric actuators are used. The ideas of combining control techniques, informatics with hydrodynamic, thermo-hydrodynamic, elasto-hydrodynamic and thermo-elasto-hydrodynamic lubrication techniques are carefully explored in this paper, considering theoretical as well as experimental aspects. The main goal of using controllable fluid film bearings is to improve the overall machine performance by: controlling the lateral vibration of rigid and flexible rotating shafts; modifying bearing dynamic characteristics, such as stiffness and damping properties; increasing the rotational speed ranges by enhancing damping and eliminating instability problems, for example, by compensating cross-coupling destabilizing effects; reducing start-up torque and energy dissipation in bearings; compensating thermal effects. It is shown that such controllable fluid film bearings can act as "smart" machine components and be applied to rotating and reciprocating machines with the goal of avoiding unexpected stops of plants, performing rotor dynamic tests and identifying model parameters "on site". Emphasis is given to the controllable lubrication (hybrid and active) applied to different types of oil film bearings under different lubrication regimes, i.e., as tilting-pad journal bearings, multi-recess journal bearings and plain journal bearings. After a comprehensive overview of the theoretical and experimental technological advancements achieved in university laboratories, the feasibility of industrial applications is highlighted, trying to foresee the future trends of such mechatronic devices.
\end{abstract}

Key words: Fluid film bearings / vibration control / friction reduction / temperature effect / stability

\section{Introduction}

Due to the development of high performance rotating machinery, growing attention has been paid to the design of new active (mechatronic) devices able to actively control vibrations and improve dynamic behaviour, i.e. magnetic bearings [1], piezoelectric bearing pushers [2$5]$, hydraulic actuator journal bearings [6-8], variable impedance bearings [9], actively controlled bearing surface profiles or simply deformable bushes [10], active journal bearings with flexible sleeves [11,12], active lubricated bearings [13-15], or pressurized bearings [16,17] among others. The rapid development of these new mechatronic devices shows that the relative maturity of many "traditional technologies" implies little or no potential for significant improvements of machine performance. Limitations to deal with the technical challenges related to some new requirements of safety, low vibration and noise

\footnotetext{
${ }^{a}$ Corresponding author: ifs@mek.dtu.dk
}

levels, demand the introduction of "non-conventional techniques" where the "conventional ones" have already reached their limits. This is especially true in the field of conventional fluid film bearings. Thus, the combination of tribology, control techniques and informatics (mechatronics) enables the development of "smart" bearings able to deal with multi-objective functions, i.e., not only the capability of supporting a rotating shaft. The synergy among different sub-areas enables balancing of various contradictory properties of integrated systems, allowing significant improvements and overcoming limitations related to "conventional" solutions. It should be underlined that many of the multi-objective functions can be activated when needed. In other words, fluid film bearings can operate conventionally most of the time, or simply be adjusted by using mechanical means [18-20]. When sensors installed in the machines detect abnormalities, the active action can be taken using mechanical, hydraulic, piezoelectric or magnetic actuators. 

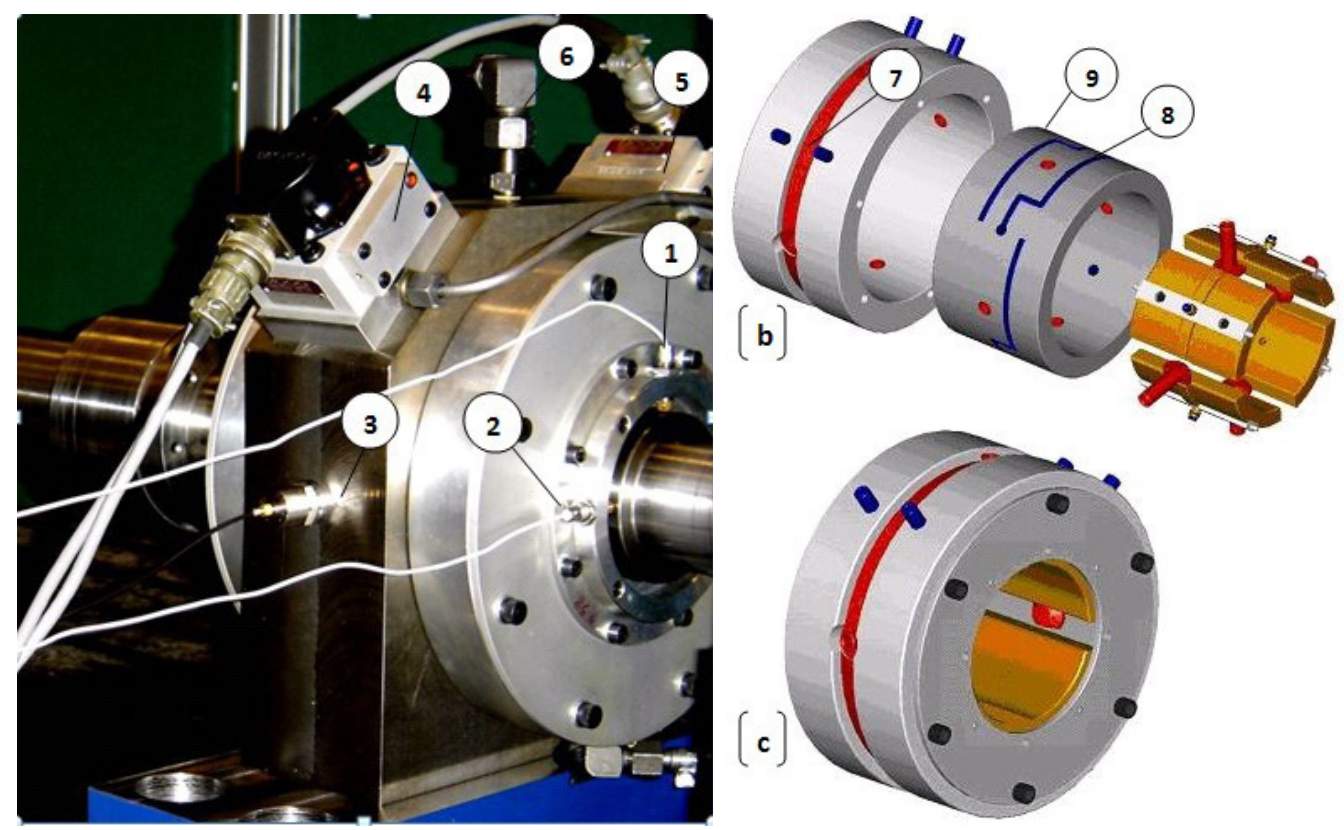

Fig. 1. Active lubricated bearing - (a) active lubricated bearing as a mechatronic device: 1 - displacement sensor (eddy-current) to measure rotor vibrations in the vertical direction; 2 - displacement sensor (eddy-current) to measure rotor vibrations in the horizontal direction; 3 - accelerometer to measure housing vibrations 4 and 5 - servo valves 6 - oil supply pipeline (conventional hydrodynamic lubrication); (b) exploded view of the bearing illustrating the channels machined inside of the housing with the aim of achieving a compact bearing: 7 channel build circumferentially to feed oil between the pads (conventional hydrodynamic lubrication); 8 and 9 - channels inside of the bearing housing connected pair wise with the servo valves (active lubrication); (c) 3D-view of the bearing as a mechanical component.

\section{Design and test of controllable fluid film bearings}

\subsection{Different types of actuation}

It is possible to distinguish two main types of actuation while designing controllable fluid film bearings: (I) actuator forces/pressures acting directly to the bearing sleeves or housing and (II) actuator pressure/flow acting between bearing sleeves and rotating shaft leading to different types of lubrication regimes. Examples of case (I) can be found in [2-5,21] using magnetic and piezoelectric pushers, in [6-8] using hydraulic actuators, and in [28-30] using mechanical means. Examples of case (II) can be found in variable impedance bearings [9], actively controlled bearing surface profiles or simply deformable bushes [10], active journal bearings with flexible sleeves [11,12], active lubricated bearings [13-15], or pressurized bearings [16,17] among others. Emphasis will be given in the case of active lubricated bearings, which allows the design and control of fluid film bearings under different lubrication regimes, namely hydrodynamic, thermo-hydrodynamic, elasto-hydrodynamic and thermoelasto-hydrodynamic.

\subsection{Actively-lubricated bearings}

When hydrostatic and hydrodynamic lubrication are simultaneously combined in a journal bearing with the aim of reducing wear between rotating and stationary parts, one refers to hybrid lubrication, which offers the advantages of both lubrication mechanisms. When part of the hydrostatic pressure is also dynamically modified by means of hydraulic control systems, one refers to active lubrication or active oil film. By the combination of fluid power, electronics and control theory, active lubrication makes simultaneously feasible the reduction of wear and the attenuation of vibration. The direct influence on the oil flow behaviour in the bearing gap is achieved by machining channels along the bearing surface or pad surface and connecting them to servo valves via pipelines. The servo valves enable changes of the fluid injection pressure directly in the bearing gap. By changing the flow characteristics through the electronic injection, one attempts to control the rotor movements, modify the stiffness and damping of the oil film or induce controllable shaft movements via calibrated oil film forces.

The design of an active lubricated tilting-pad journal bearing is shown in Figure 1: the compactness, as it can be seen in Figure 1c, is an advantage. The capability of generating high control forces, without the need of additional backup bearings in case of control failure, gives high operational reliability. I.e. they are also able to operate passively (without control). The length of pipelines connecting the servo valves and oil film gap is significantly reduced by machining channels inside of the bearing housing, as illustrated in detail in Figure 1b. The displacement sensors 1 and 2 capture the lateral vibrations of the rotor in the vertical and horizontal directions respectively, as 
illustrated in Figure 1a. The accelerometer 3 mounted on the bearing housing detects bearing housing vibrations in the horizontal direction. The servo valves 4 and 5 are used to control the pressurized oil injection. The pressurized oil flows through the channels machined inside the bearing housing, namely channels 8 and 9 , into the bearing gap by means of orifices machined in the middle of the pads. In industrial bearings such a type of orifice is normally of use to hydrostatic lubrication under start up conditions. The channels 8 and 9 connected to servo valves 4 and 5 by a differential principle make possible the generation of time-dependent control forces.

The pads are oriented for load-between-pads configuration, in this case 45 degrees from the vertical static load. Therefore, the oil injection will occur with an angle of 45 degrees from the vertical or horizontal directions. Such an oil injection will be controlled using the information coming from the sensors 1, 2, 3 and other sensors mounted along the flexible rotating shaft. The (conventional) hydrodynamic lubrication will always be operating. Thus, the bearing can operate passively as well as actively. The conventional hydrodynamic lubrication will be created by feeding the oil with low pressure (up to $0.2 \mathrm{MPa}$ ) via the pipeline connector 6 and the channel 7. The oil will reach the bearing gap through holes machined between the four pads. The orifices are machined 90 degrees from each other connecting the channel 7 and the space between the four tilting-pads.

\section{Applications}

\subsection{Active vibration control of flexible shafts via actively-lubricated tilting-pad bearings}

The design and implementation of active control of flexible rotating shafts via active bearings is not a trivial task. It has to be carefully carried out and demands multidisciplinary knowledge, typical when dealing with mechatronics. In this case, knowledge in the field of rotor dynamics, fluid film bearings, fluid power and control techniques has to be combined. This is quite challenging from the industrial applications viewpoint. Normally the control design for laboratory is based on adjusted and updated mathematical models. This avoids a series of implementation problems, among others instability and spillover, a problem well-known in the literature. Moreover, significant reduction of damping factor of specific mode shapes can occur, while other mode shapes become very badly damped.

Figure 2 illustrates the experimental frequency response function for the flexible rotating shaft controlled by the active lubricated tilting-pad journal bearing. Figure 2a highlights a test rig with the auxiliary bearing (element 1), the electromagnetic shaker (element 2), the actively-lubricated bearings (element 3 ) and the flexible rotating shaft (element 4 ). The rotor-bearing system is excited at the shaft extremity where the auxiliary bearing is attached. The excitation force and the vibration response of this extremity of the shaft are measured
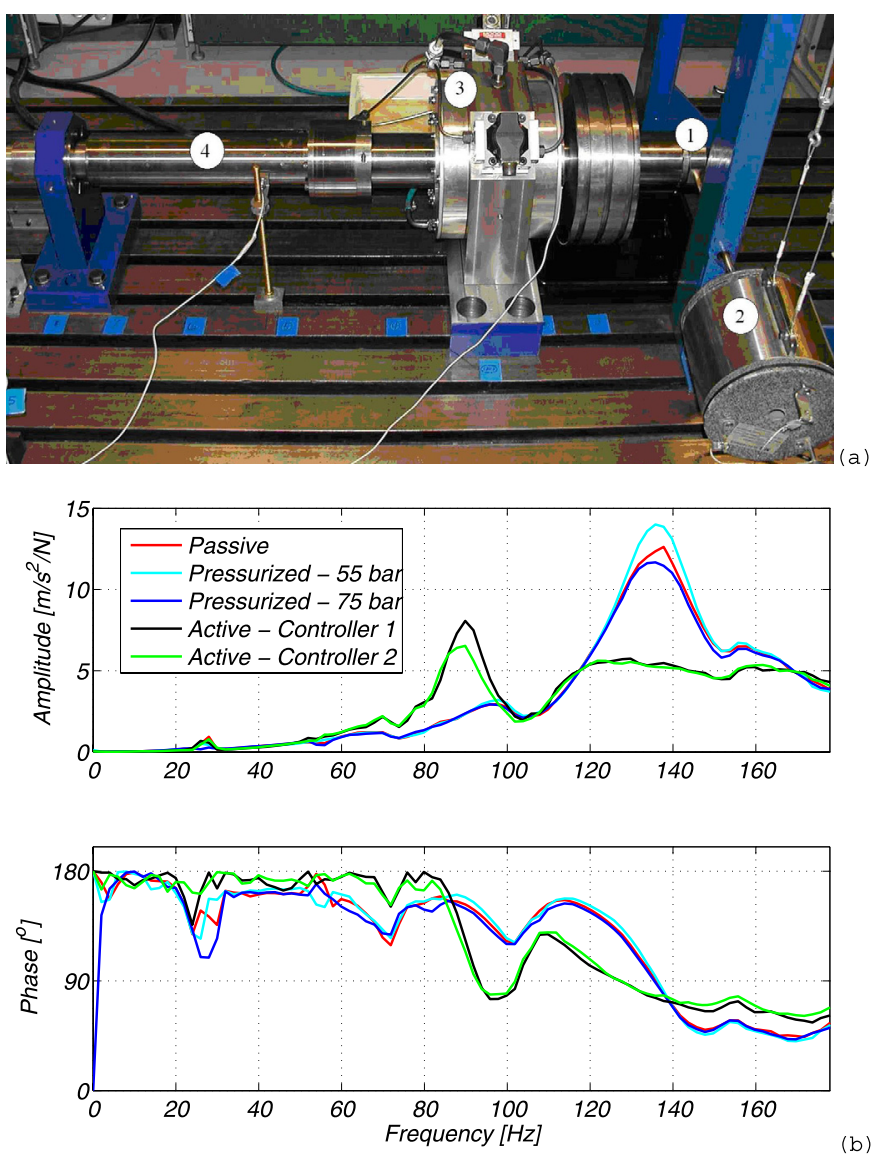

Fig. 2. Experimental results for a flexible rotating shaft controlled by means of an active lubricated bearing - (a) test rig illustrating the auxiliary bearing (element 1 ), the electromagnetic shaker (element 2), the actively-lubricated journal bearing (element 3) and the flexible rotating shaft (element 4); (b) experimental frequency response function of node 1 (auxiliary bearing) when the rotor-bearing system operates at rotational speed of $3000 \mathrm{rpm}(50 \mathrm{~Hz})$ in five different cases: (i) passively or conventionally lubricated; (ii) hybrid lubricated with a hydrostatic pressure of 55 bar (5.5 MPa); (iii) hybrid lubricated with a hydrostatic pressure of 75 bar (7.5 MPa); (iv) actively lubricated using a PD-feedback control and a supply pressure of 75 bar; (v) actively lubricated using a PD-feedback control and a supply pressure of 100 bar (10 MPa).

using a force transducer and an accelerometer respectively. Figure $2 \mathrm{~b}$ shows the experimental frequency response function of the shaft extremity (auxiliary bearing) when the rotor-bearing system operates at rotational speed of $3000 \mathrm{rpm}(50 \mathrm{~Hz})$ under five different lubrication regimes: (i) passively or conventionally hydrodynamic lubricated; (ii) hybrid lubricated (pressurized) with a hydrostatic pressure of 55 bar (5.5 MPa); (iii) hybrid lubricated with a hydrostatic pressure of 75 bar $(7.5 \mathrm{MPa})$; (iv) actively lubricated using a PD-feedback control and a supply pressure of 75 bar (7.5 MPa); (v) actively lubricated using a PD-feedback control and a supply pressure of 100 bar $(10 \mathrm{MPa})$. It is important to highlight that the proportional-derivative (PD) controller is built with 
regard to the lateral displacement and lateral velocity of the shaft extremity. Such signal is obtained by integrating the acceleration of shaft extremity (auxiliary bearing), measured by using an accelerometer attached to the auxiliary bearing. The system resonance amplitude around $130 \mathrm{~Hz}$ is very significantly attenuated (almost by a factor 2) when the system operates under active lubrication regime. Nevertheless, the other resonance around $90 \mathrm{~Hz}$ is amplified. New control strategies are being investigated for attenuating the vibration of flexible rotating shaft in the frequency range up to $200 \mathrm{~Hz}$.

\subsection{Feasibility of industrial applications of actively- lubricated tilting-pad journal bearings - gas compressors and steam turbines}

Active magnetic bearings [1], hybrid tilting-pad thrust bearings [17, 22, 23], ball bearings controlled by active chamber systems $[24,25]$ are already under operation in some types of rotating machines.

In terms of industrial applications, it is important to highlight that tilting-pad bearings are the most stable among the different types of journal bearings. Normally, when vibration instabilities arise in a rotating machine supported by plain hydrodynamic bearings, the journal bearings are exchanged for tilting-pad bearings. If further actions shall be taken towards improving rotor-bearing stability, control techniques can be applied to a journal bearing that already presents the best stability properties.

The feasibility of reducing lateral vibrations of an industrial gas compressor by using an active lubricated tilting-pad journal bearing is investigated in [26]. The rotating machine whose dynamics are analyzed is a gas compressor composed of five impellors, of total mass $391 \mathrm{~kg}$ and operates in the range of $6942 \mathrm{rpm}(115.7 \mathrm{~Hz})$ to $10,170 \mathrm{rpm}(169.7 \mathrm{~Hz})$. It is possible to control the first bending vibration mode of a flexible rotor via its bearings. Despite the limitation of rotor displacements in the bearing gap (30\% of the assembled clearance), it is possible to reduce the rotor vibration by active forces (active lubrication) acting on the bearings.

\subsection{Feasibility of industrial applications of actively- lubricated multirecess bearings - gas compressors and steam turbines}

Multi-recess journal bearings with two pairs of active pockets are also another kind of controllable fluid film bearing $[16,27]$. In terms of industrial application, the importance of hybrid journal bearings as potential applications as load support elements in high-speed turbomachinery and machine tool spindles has steadily grown over the past years. Hybrid bearings enable high-load capacity with large direct stiffness, accuracy of positioning, low friction and long life. Such properties make them attractive for applications from reactor coolant pumps to precision grinder spindles.
Further improvement of rotor-bearing stability using active lubricated multi-recess bearings is discussed in [23], using the same industrial gas compressor presented in [22]. The American Petroleum Institute (API) Standard 617 is commonly used in the oil and gas industry, guiding engineers to set alarm limits for lateral vibration of rotating machines. According to the API 617 standard, the vibration amplitude limit for the case of the gas compressor under investigation is $16 \mu \mathrm{m}$. The bearing operates with different values of supply pressure. For low values of pressure 1.5 or 2.0 MPa, the unbalance responses of the compressor are in accordance with API limit, even at critical speeds, but for higher values of 3.0 or $4.0 \mathrm{MPa}$, the unbalance response of the compressor at critical speeds is higher than the API limit. In the special case of multi-recess journal bearings, an increase of the supply pressure will necessarily lead to a simultaneous increase of the stiffness coefficients of the bearing. By increasing the stiffness of the bearings, only small relative movements between compressor shaft and bearing housing will be possible in such modes. This will deteriorate the capability of dissipation of vibration energy from oil film squeeze in the bearings and will reduce the damping ratio.

From the viewpoint of active lubrication applied to multi-recess journal bearings with the aim of controlling lateral dynamics of flexible rotors, a paradox is reached: (a) to improve the performance of the active lubrication in such special kind of bearings high values of supply pressure are needed, once the saturation of control signals retrofitted to the servo valves limits the range in which the bearing dynamics coefficients can be modified. Nevertheless, by increasing the supply pressure the main stiffness coefficients of the bearing will also increase; (b) to reduce lateral vibrations of the flexible rotating machine it is very important to allow relative large amplitudes of vibration in the bearings, in order to increase the dissipation of vibration energy by squeezing the oil film. It means that it is important to keep low values of main stiffness coefficients, which implies working with low values of supply pressure. With low supply pressure the efficiency of the active lubrication will be significantly reduced or unnecessary.

\subsection{Feasibility of applications of actively-lubricated planar bearings - reciprocating machines}

The feasibility of using active lubrication in reciprocating machines is also theoretically investigated in [28]. Mathematical models of hermetic reciprocating compressors are developed, combining multibody dynamics, finite-element method and fluid film lubrication. Different constraint equations are used to accommodate multibody dynamics and fluid film bearings and correctly describe the dynamic behaviour of mechanical systems. The equations describing the dynamics of hermetic compressor components (obtained based on a multibody system approach) are coupled to the controllable thin fluid film and different control strategies are simulated and discussed. 

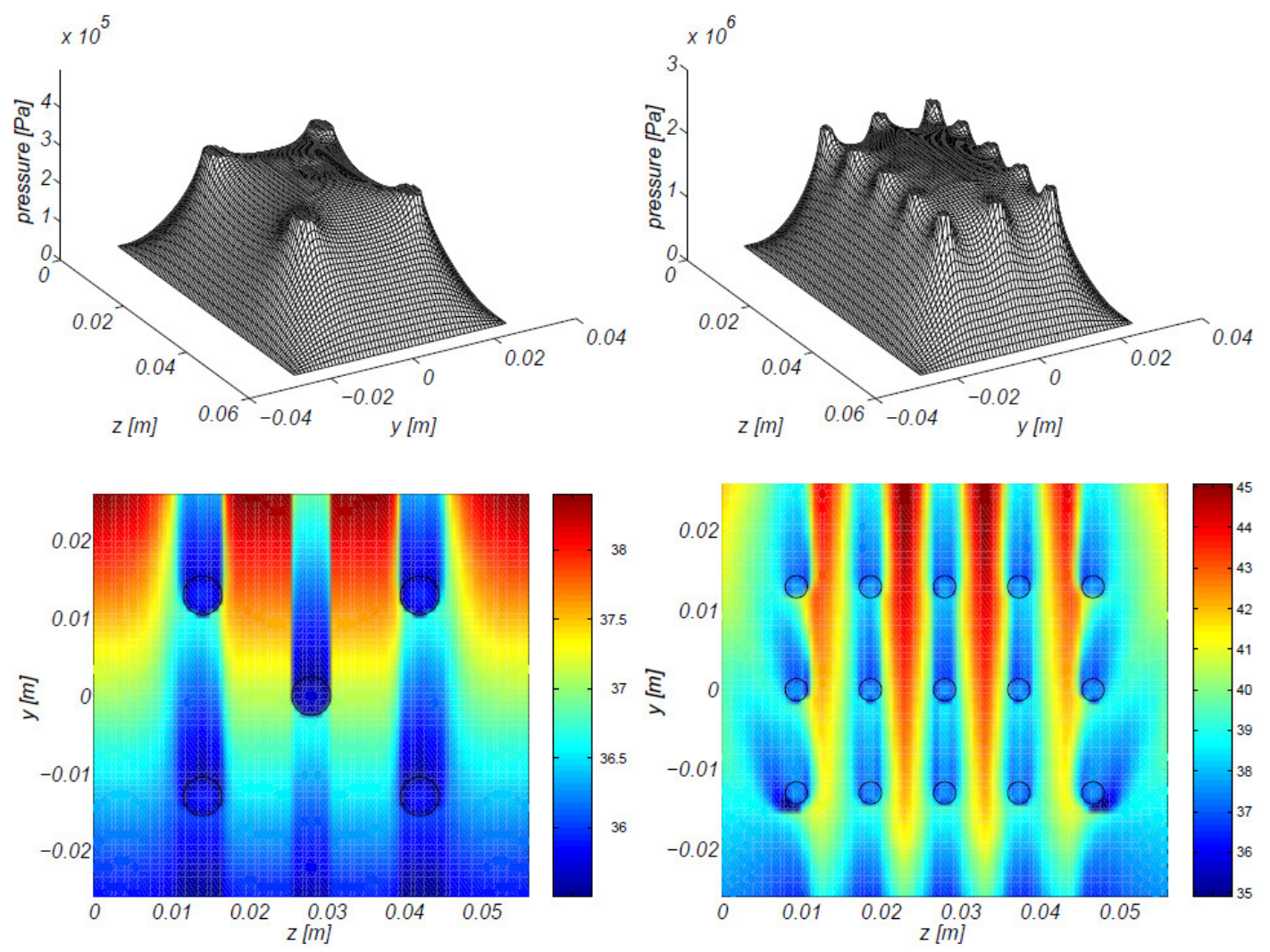

Fig. 3. Theoretical results - compensation of thermal effects: (a) pad surface with 5 five orifices; (b) pad surface with 15 orifices.

An overview about the application of active lubrication techniques to different types of journal bearings is given. Depending on the system size, servo valves can be substituted by piezo-injectors in order to obtain more compact systems. Increasing the oil film thickness and reducing the rotor orbits inside of the bearings can lead to a significant reduction of friction and vibrations. The theoretical results are very promising. Nevertheless, experimental results are necessary and needed in order to validate assumptions made during the development of the mathematical models.

\subsection{Exploring thermal effects in hybrid or actively- lubricated tilting-pad journal bearings}

In [29] thermo-hydrodynamic analysis is carried out for the case of hybrid-lubricated tilting-pad journal bearings with multiple orifices. At light loading conditions, low rotor angular velocities and low injection pressures one obtains the best cooling effects on the pad surface by applying radial oil injection. Increasing the injection pressure at low rotor angular velocities, one achieves an increase of the oil temperature inside the orifices due to an increase of the viscous dissipation (high injection velocities). By increasing the rotor angular velocity and consequently the hydrodynamic pressures, outlet flow into the orifices can be detected if the injection pressure is lower. Moreover, no cooling effect over the pad surface is observed in such a case. Although the injection pressure could overcome the hydrodynamic pressure, resulting in inlet flow of the cooled oil into the bearing gap, the cooled area over the pad would be restricted to the tangential direction. Such an effect is a consequence of the predominant lubricant flow in the tangential direction and is clearly illustrated in Figures $3 \mathrm{a}$ and b, with 5 and 15 orifices distributed over the pad surface. It is shown in [29] that the positions of the orifices play a very important role on the cooling effect over the pads, but such effect is locally detectable ahead of the orifices, in the pad longitudinal direction. For the temperature distribution, it is better to machine the orifices close to the edges, where the hydrodynamic pressures are lower and an inlet flow of the cooled oil into the bearing gap is more easily ensured. Regarding the dimension of the orifices, a large reduction of their diameter may cause an increasing of the viscous dissipation inside the orifices and thus, a further reduction of the bearing cooling effect is expected.

\subsection{Feasibility of applying active lubrication to compressible fluid film bearings}

Modern turbo-machinery applications, high speed machine tools and laboratory equipment require nowadays ever-growing rotational speeds and high degrees of precision and reliability. Gas journal bearing have been adopted in these applications as they can perform 
efficiently at high speeds and in clean environments. However, they have drawbacks of poor carrying capacity and low damping, which often translate to a reduced range of stability. In order to enhance these characteristics, one solution is to combine the hydrodynamic effect with the addition of external controllable pressurization. Piezoactuated valves are used in order to inject pressurized air into the bearing gap through orifices located on the bearing walls. A modified form of the compressible Reynolds equation for active lubrication helps significantly while designing such a mechatronic device. Experimental results are future aspects of the research and will be needed to validate different assumptions adopted during the mathematical modelling [30].

\subsection{Feasibility of using elastohydrodynamics in actively-lubricated bearings}

The static, stationary linear harmonic responses and stability of tilting-pad journal bearings have been investigated in $[15,31]$. Different orifice configurations with 1, 2, 4 and 6 orifices have been investigated with the aim of exploring the differences in static and dynamic performance. It seems that a four orifice configuration is more powerful in a proportional regulated system, while a 6 orifice configuration is more powerful in a derivative regulated system [31]. Orifices placed far from the pivot line, can increase the effective static preload factor of a tilting-pad journal bearing. Since pad compliance increases in importance for increasing frequency, this result extends to the dynamic case [15].

\section{Conclusions}

Theoretical and experimental studies show that the performance of rotating machines can be significantly enhanced by using controllable fluid film bearings. Such bearings can operate conventionally most of the time, and when sensors installed in the machines detect abnormalities, the active action can take place, using mechanical, hydraulic, pneumatic, piezoelectric or magnetic actuators. While the design of such bearings is relatively simple, the implementation and calibration are challenging, demanding engineers with multidisciplinary skills and a solid integrated-knowledge in rotordynamics, tribology, instrumentation and control techniques (mechatronics).

\section{References}

[1] E.H. Maslen, Magnetic bearings - theory, design and application to rotating machinery, New York, USA, Springer, 2009

[2] A.B. Palazzolo, R.R. Lin, R.M. Alexander, A.F. Kascak, J. Montague, Test and theory for piezoelectric actuators - active vibration control of rotating machinery, Trans. ASME, J. Vibr. Acoust. 113 (1991) 167-75
[3] H. Ulbrich, J. Althaus, Actuator design for rotor control. In 12th biennial ASME conference on vibration and noise, 1989, pp. $17-21$

[4] D.C. Deckler, R.J. Veillette, M.J. Braun, F.K. Choy, Simulation and control of an active tilting-pad journal bearing, STLE Trib. Trans. 47 (2000) 440-458

[5] A. Wu, Z. Cai, M.S. de Queiroz, Model-based control of active tilting-pad bearings, IEEE/ASME Trans. Mechatroni. 12 (2007) 689-695

[6] J. Althaus, Eine aktive hydraulische Lagerung für Rotorsysteme, Düsseldorf, Germany: VDI-Verlag, 1993

[7] I. Ferreira Santos, Aktive Kippsegmentlagerung - Theorie und Experiment, Düsseldorf, Germany, VDI-Verlag, 1993

[8] I. Ferreira Santos, On the adjusting of the dynamic coefficients of tilting-pad journal bearings, STLE Trib. Trans. 38 (1995) 700-706

[9] M.J. Goodwin, T. Boroomand, C.J. Hooke, Variable impedance hydrodynamic journal bearings for controlling flexible rotor vibrations, In 12th biennial ASME conference on vibration and noise, 1989, pp. 261-267

[10] H.G. Rylander, M.J.T. Carlson, C.R. Lin, Actively controlled bearing surface profiles - theory and experiment, in ASME Tribology symposium, 1995, pp. 11-14

[11] L. Sun, J.M. Krodkiewski, Experimental investigation of dynamic properties of an active journal bearing, J. Sound Vib. 230 (2000) 1103-1117

[12] J.M. Krodkiewski, G.J. Davies, Modelling a new threepad active bearing, in: Proc. ASME Turbo Expo 2004, pp. 1-9

[13] I. Ferreira Santos, F.H Russo, Tilting-pad journal bearings with electronic radial oil injection, ASME J. Tribol. 120 (1998) 583-594

[14] I. Ferreira Santos, R. Nicoletti, A. Scalabrin, Feasibility of applying active lubrication to reduce vibration in industrial compressors, ASME J. Eng. Gas Turbine Power 126 (2004) 888-894

[15] A.M. Haugaard, I. Ferreira Santos, Elastohydrodynamics applied to active tilting-pad journal bearings, ASME J. Tribol. 132 (2010) 021702-1-021702-10

[16] D.E. Bently, T. Eldridge, J. Jensen Mol, Active controlled hydrostatic bearings for a new generation of machines, in: ASME/IGTI international gas turbine and aeroengine congress and exhibition, Munich, Germany, 2000, 2000GT-354

[17] I. Ferreira Santos, A Fuerst, Grosse Axiallager mit Hybridschmierung - Theoretische und experimentelle Betrachtungen, in: Schwingungen in rotierenden Maschinen, edited by $H$. Irretier, R. Nordmann, H. Springer, Vieweg Verlag, Braunshweig, Germany, 2003, Vol. 6, pp. 51-60

[18] J.K. Martin, D.W. Parkins, Theoretical studies of a continuously adjustable hydrodynamic fluid film bearing. ASME Trans, J. Tribol. 124 (2002) 203-211

[19] J.K. Martin, D.W. Parkins, Testing of a large adjustable hydrodynamic journal bearing, STLE Trib. Trans. 44 (2001) 559-566

[20] J.K. Martin, A mathematical model and numerical solution technique for a novel adjustable hydrodynamic bearing. Int. J. Numer. Meth. Fluids 28 (1999) 845-864

[21] T. Stolarski, Self-lifting contacts: from physical fundamentals to practical applications, Proc. Institution of Mechanical Engineers, Part C: J. Mech. Eng. Sci. 220 (2006) 1211-1218 
[22] N. Heinrichson, I. Ferreira Santos, A. Fuerst, The influence of injection pockets on the performance of tilting-pad thrust bearings: part I - theory, ASME Trans. J. Tribol. 129 (2007) 895-903

[23] N. Heinrichson, A. Fuerst, I. Ferreira Santos, The influence of injection pockets on the performance of tilting-pad thrust bearings: part II - comparison between theory and experiment, ASME Trans. J. Tribol. 129 (2007) 904-912

[24] J. Althaus, P. Stelter, B. Feldkamp, H. Adam, Aktives hydraulisches Lager für eine Schneckenzentrifuge, Schwingungen in rotierenden Maschinen, H. Irretier, R. Nordmann, (éd.) Springer, Vieweg Verlag 1993, Vol. 2, pp. $28-36$

[25] W.H.N. Hagemeister, Auslegung von hochdynamischen servohydraulischen Antrieben für eine Aktive Frässpindellagerung, O+P Ölhydraulik und Pneumatik, 44 (2000) 23

[26] I. Ferreira Santos, R. Nicoletti, A Scalabrin, Feasibility of applying active lubrication to reduce vibration in industrial compressors, ASME Trans. J. Eng. Gas Turbine Power 126 (2004) 888-894
[27] I. Ferreira Santos, F.Y. Watanabe, Lateral dynamics and stability analysis of a gas compressor supported by hybrid and active lubricated multirecess journal bearing, J. Brazilian Soc. Mech. Sci. Eng. 28 (2006) 486-496

[28] E.A. Estupinan, I. Ferreira Santos, Linking rigid multibody systems via controllable thin fluid films, Tribol. Int. 42 (2009) 1478-1486

[29] I. Ferreira Santos, R Nicoletti, THD analysis in tiltingpad journal bearings using multiple orifice hybrid lubrication. ASME Trans. J. Tribol. 121 (1999) 892-900

[30] S. Morosi, I. Ferreira Santos, Stability analysis of flexible rotors supported by hybrid permanent magnet - gas bearings, in: PACAM XI - 11th Pan-American Congress of Applied Mechanics, January 4-8, Foz de Iguacu, PR Brazil, 2010, pp. 1-8

[31] M.A. Haugaard, I. Ferreira Santos, Multi-orifice active tilting-pad journal bearings - harnessing of synergetic coupling effects, Trib. Int. 43 (2010) 1374-1391 